\title{
Bacterial endophthalmitis following 25-gauge transconjunctival sutureless vitrectomy
}

\section{Drew N Sommerville \\ Dean P Hainsworth}

The Mason Eye Institute, University of Missouri, Columbia, Missouri, USA
Correspondence: Dean P Hainsworth Mason Eye Institute, One Hospital Drive, Columbia, MO 65212, USA

Tel +I 5738821027

Fax +l 5738828474

Email hainsworthd@health.missouri.edu
Purpose: To report a case of endophthalmitis following 25-gauge transconjunctival sutureless vitrectomy.

Design: Observational case report.

Methods: An 87-year-old male who underwent sutureless 25-gauge vitrectomy developed unilateral endophthalmitis. Vitreous culture revealed Staphylococcus coagulase-negative bacteria. He was subsequently treated with intravitreal antibiotics and oral prednisone.

Results: The endophthalmitis resolved with a best corrected visual acuity of $6 / 200$ with the presence of an epiretinal membrane.

Conclusions: Possible contributing factors to endophthalmitis following sutureless vitrectomy include decreased vitreous irrigation/lavage, lack of a watertight wound, and/or vitreous wicking, all of which may promote intraocular bacterial entrance. A sutureless vitrectomy system may increase the risk of vitrectomy-associated endophthalmitis.

Keywords: endophthalmitis, 25-gauge vitrectomy, vitreous wick, sutureless, high flow lavage

We have seen much in the literature recently about the 25 -gauge transconjunctival sutureless vitrectomy system (TSV), which is quickly replacing many 19-gauge vitrectomy procedures (Fugii et al 2002). The TSV system allows for smaller wounds, reduced operative times, and theoretically less post-operative inflammation; however there may be adverse outcomes associated with decreased sclerotomy size. To our knowledge, there have been only a few reported cases of endophthalmitis following 25-gauge TSV (Taylor and Aylward 2005; Taban et al 2006; Acar et al 2007; Kunimoto et al 2007; Valmaggia 2007).

We recently performed a 25-gauge vitrectomy on an 87-year-old male in order to remove persistent dense vitreous hemorrhage associated with cataract surgery. His periorbital skin, eyelids, and conjunctiva were prepped pre-operatively with $5 \%$ povidone-iodine solution, but no sub-conjunctival injection of antibiotics was given at the end of the surgery. The vitrectomy was without any intraoperative complications and the operative time was 27 minutes. The vitreous was thoroughly removed, leaving only a small amount of vitreous skirt. Approximately thirty hours later he developed severe eye pain and vision was reduced to hand motion in the operative eye. Marked cell and flare with dense vitritis were present. Acute post-operative endophthalmitis was diagnosed and a vitreous tap was performed, followed by intravitreal injection of $1.0 \mathrm{mg}$ vancomycin and $2.0 \mathrm{mg}$ ceftazidime, as well as initiation of topical gatifloxacin. The vitreous culture grew coagulase-negative Staphylococcus, sensitive to all of the above antibiotics. The inflammation gradually improved with antibiotic and prednisone drops and eight months after injection his vision was 6/200 with a quiet eye and epiretinal membrane present. 
Endophthalmitis is rare following 19- or 20-gauge vitrectomy with $0.07 \%$ incidence reported (Cohen et al 1995). The reason endophthalmitis rates following traditional vitrectomy surgery are historically low when compared to cataract surgery is unknown. A contributing factor may be greater vitrectomy irrigation fluid volumes, allowing dilution of potential pathogens. The smaller incision diameter of the TSV system ( $0.57 \mathrm{~mm}$ versus $0.9 \mathrm{~mm}$ in 19-gauge) results in infusion rates decreased by a calculated factor of 6.9 (Fugii et al 2002). Infusion fluid volume reduction during 25-gauge vitrectomy surgery may increase risk for bacterial infection.

Endophthalmitis following TVS vitrectomy may result from sutureless scleral wounds, mimicking risks inherent with sutureless clear cornea cataract extraction. Endophthalmitis rates following clear cornea cataract surgery are substantially higher than those seen after limbal incision surgery (Taban et al 2005). Intraocular pathogens may result from relative post-operative hypotony creating negative pressure through a nonwatertight wound, thus allowing retrograde intraocular flow of bacteria. Sutureless vitrectomy with nonwatertight incisions often results in relative hypotony with resultant possible similar retrograde bacterial seeding.

Endophthalmitis following TVS vitrectomy surgery may also be the result of a "vitreous wick". Vitreous adherent to a 19- or 20-gauge sclerotomy site is excised prior to closure. TSV vitrectomy results in vitreous incarceration at the sclerotomy site. Early cataract surgery demonstrated that a "vitreous wick" allows entrance of bacteria with resultant endophthalmitis (Ruiz and Teeters 1970).

While 25-gauge vitrectomy is an exciting tool, its use has the potential to increase the rate of vitrectomy associated endophthalmitis. The smaller incisions and shorter surgical times seen increasingly in retinal surgery mimic the sweeping evolution observed in cataract surgery. As in sutureless cataract surgery, 25-gauge sutureless vitrectomy may result in an increased rate of endophthalmitis as compared with vitrectomies involving sutured sclerotomies.

\section{Disclosure}

Supported in part by an unrestricted grant from Research to Prevent Blindness, Inc., New York, NY. The authors have no proprietary interest in any aspect of this paper. There are no conflicts of interest.

\section{References}

Acar N, Unver YB, Altan T, et al. 2007. Acute endophthalmitis after 25-gauge sutureless vitrectomy. Int Ophthalmol, 27:361-3.

Cohen SM, Flynn HW, Murray TG, et al.; The Postvitrectomy Endophthalmitis Study Group. 1995. Endophthalmitis after pars plana vitrectomy. Ophthalmology, 102:705-12.

Fugii GY, de Juan Jr E, Humayun MS, et al. 2002. A new 25-gauge instrumentation system for transconjunctival sutureless vitrectomy surgery. Ophthalmology, 109:1807-13.

Kunimoto DY, Kaiser RS, Wills Eye Retina Service. 2007. Incidence of endophthalmitis after 20- and 25-gauge vitrectomy. Ophthalmology, 114:2133-7.

Ruiz RS, Teeters VW. 1970. The vitreous wick syndrome. Am J Ophthal$\mathrm{mol}, 70: 483-90$

Taban M, Behrens A, Newcomb RL, et al. 2005. Acute endophthalmitis following cataract surgery. Arch Ophthalmol, 123:613-20.

Taban M, Ufret-Vincenty RL, Sears JE. 2006. Endophthalmitis after 25-gauge transconjunctival sutureless vitrectomy. Retina, 26:830-1.

Taylor SRJ, Aylward GW. 2005. Letter of correspondence: endophthalmitis following 25-gauge vitrectomy. Eye, 19:12280-9.

Valmaggia C. 2007. Pars plana vitrectomy with 25 -gauge instruments in the treatment of idiopathic epiretinal membranes. Klinische Monatsblätter fur Augenheilkunde, 224:292-6. 